\title{
Structure of packed bed probed by Micro-Computed tomography, and Collision Guided Packing
}

\author{
Aashna Suneja ${ }^{1}$ and Shantanu Roy ${ }^{1}$ \\ ${ }^{1}$ Indian Institute of Technology Delhi
}

January 22, 2022

\begin{abstract}
The internal structure of packed beds formed by different arrangements of packings has been a subject of study for the past several decades. In this study, we have attempted to investigate the structure formed in laboratory-scale packed beds through experimentation and modeling, employing different ways of packing the bed. The structure has been measured using MicroComputed Tomography (Micro-CT) and characterized through appropriate metrics. The "filling of the bed" has been modeled using a technique called Collision Guided Packing (CGP). Thus, this contribution combines both high resolution measurements as well as detailed particle-based models, bringing out a head-to-head comparison of the bed filling process and also how the final bed is configured (its structure). The work stands as an independent piece, but also provides the basis for a rigorous understanding of the impact of bed filling on deep hydroprocessing, wherein the bed structure is known to have a dramatic effect.
\end{abstract}

\section{Hosted file}

Structure of packed bed probed by Micro-CT - FINAL.docx available at https://authorea. com/users/456638/articles/553631-structure-of-packed-bed-probed-by-micro-computedtomography-and-collision-guided-packing

\section{Hosted file}

ISCRE 2021 figures - v3.pptx available at https://authorea.com/users/456638/articles/553631structure-of-packed-bed-probed-by-micro-computed-tomography-and-collision-guided-packing 